\title{
Bioavailability and Solubility of Different Calcium-Salts as a Basis for Calcium Enrichment of Beverages
}

\author{
Gaby Kressel*, Maike Wolters, Andreas Hahn \\ Institute of Food Science and Human Nutrition, Leibniz University of Hannover, Hannover, Germany. \\ Email: kressel@nutrition.uni-hannover.de \\ Received July $13^{\text {th }}, 2010$; revised August $26^{\text {th }}, 2010$; accepted October $9^{\text {th }}, 2010$.
}

\begin{abstract}
Background: When usual calcium consumption patterns were analysed most people in the U.S. and Europe consume less than the recommended daily allowance. Supplements and fortified foods offer alternative and additional sources of calcium to traditional food. Calcium carbonate is the most common supplement but it is less soluble in water and, therefore, not suitable for enrichment of beverages. New organic calcium salts have a better solubility but less is known about their bioavailability. In the present study, we assessed the solubility and bioavailability of the new organic calcium salts, calcium lactate citrate and calcium lactate malate, in comparison to the traditional supplements, calcium carbonate and calcium gluconate. Design: Randomized, single-blind, four way cross-over study comparing single doses of $500 \mathrm{mg}$ calcium in the form of four different calcium-salts. Subjects were advised to consume $25 \mu \mathrm{g}$ vitamin D 3 daily two weeks prior to the start of the study and during the whole study period. Subjects: 20 healthy young men, Methods: Blood samples were drawn immediately before and 2, 4, 6, 8, 12 and $24 \mathrm{~h}$ after ingestion of the calcium preparation. Concentration of total calcium and intact parathyroid hormone were measured in the serum. Urine was collected at baseline and during the intervals 0-3, 3-6, 9-15 and 15-24 $h$ and excretion of calcium, sodium and creatinine was examined. Results: The tested new salts were easily water soluble, significantly better than calcium gluconate. Calcium carbonate is almost insoluble. The bioavailability of the four different calcium salts was found to be almost identical. The maximum total serum calcium increased by $7.6 \%$ two hours after ingestion calcium lactate citrate, by $7.4 \%$ after calcium lactate malate, by $5.5 \%$ after calcium carbonate, and by $5.8 \%$ after calcium gluconate. Intact parathyroid hormone concentration showed the expected depression for calcium lactate citrate, calcium lactate malate and calcium carbonate, whereas the serum level was significantly higher after ingestion of calcium gluconate. Conclusion: Given an almost equivalent bioavailability of the four tested calcium salts, we conclude that the new salts calcium lactate citrate and calcium lactate malate are well suited for fortification of beverages and thus to increase the average daily calcium intake.
\end{abstract}

Keywords: Calcium Salt, Bioavailability, Solubility, Enrichment of Beverages

\section{Introduction}

Calcium (Ca) accounts for 1 to $2 \%$ of adult human body weight and is one of the major mineral components of the skeletal system. Small but essential quantities of calcium are required for nerve conductivity, muscle contraction, hormone and enzyme secretion, and blood clotting. Adequate $\mathrm{Ca}$ intake is essential for normal growth and development of the skeleton and teeth, and for adequate bone mineralization. In adulthood, low calcium intake has been associated with increased risk of osteoporosis and bone fractures $[1,2]$. The recommended die- tary allowance (RDA) in adults for calcium varies between $800-1300 \mathrm{mg} / \mathrm{d}$ for adolescents, depending on the country, and $1000 \mathrm{mg} / \mathrm{d}$ for adults rising to $1200 \mathrm{mg} / \mathrm{d}$ for the elderly [2-5].

When usual calcium consumption patterns were analyzed, most population groups consumed less than the RDA. Only $32 \%$ of the US adults (exclusive of water and supplements) and $50 \%$ of the German adults (inclusive of water and supplements) met the adequate intake for calcium $[1,6]$. Data from NHANES (National Health and Nutrition Examination Survey) provides information on the intake of calcium from all sources, including diet and 
supplement use. Thus, about $43 \%$ of Americans take calcium supplements, with an average daily intake of 331 $\mathrm{mg} / \mathrm{d}[1,7]$. Supplements and fortified foods offer alternative sources of calcium to traditional food and in many cases show an improved absorbability [8]. However, such alternative sources of calcium need to be evaluated in respect of bioavailability, solubility, cost, tolerance, convenience, taste, and compatibility with foods [9]. The most common Ca-supplement is calcium carbonate (CC) $[10,11]$; other available calcium salts are calcium gluconate (CG), calcium malate, calcium lactate, and calcium fumarate, or mixed salts such as calcium citrate malate, calcium lactate malate (CLM) and calcium lactate citrate (CLC).

$\mathrm{CC}$ is generally the least expensive and the most widely-used calcium salt. Eighty-five percent of all calcium supplements sold in the US contains calcium carbonate. CC comes in swallowable tablets and in chewable form, but its solubility is marginal and, thus, it is not suitable for fortification of fruit juices and other beverages. CG is an organic water-soluble calcium salt of gluconic acid. Data on the absorbance and bioavailability are scarce. Two studies conclude a quite similar absorption of CG to that of milk, CC, Ca acetate, Ca fumarate, or Ca lactate $[12,13]$. Nevertheless it is not often used to fortify beverages due to its low calcium content $[11,14$, 15]. CLM and CLC are mixed salts of calcium lactate with malic acid and citric acid, respectively, which offer very good water solubility. Hence, these salts can be used to fortify fruit juices and beverages.

However, no information is available concerning the the bioavailability and absorption rate of calcium from CLM or CLC. Therefore, the aim of this study was to compare the absorption of calcium after a single dose of CLM, CLC, CG, or CC in healthy male adults.

\section{Material and Methods}

\subsection{Solubility}

Firstly, the concentration of $\mathrm{Ca}$ in each salt and the recommended daily intake based on the $\mathrm{Ca}$ amount was calculated. The solubility of different calcium salts was tested in $21^{\circ} \mathrm{C}$ pure water and filtered apple juice (becker's bester, Germany). The maximum dissolvable amount of each salt in $100 \mathrm{ml}$ water was detected producing a saturated solution of each salt (5 min shaking). The solubility tests were repeated three times in the same conditions. The amount of dissolved $\mathrm{Ca}$ in every saturated solution was calculated afterwards.

\subsection{Bioavailability}

\subsubsection{Subjects}

Twenty healthy male adults, aged 20 to 41 years, were recruited by advertising. The volunteers were free of chronic diseases such as bowel disease, intestinal resection, malabsorption, regional enteritis, or chronic diarrhea. None of the subjects took vitamin or mineral supplements, laxatives, anticoagulants, or other medications that could affect calcium or vitamin D serum concentrations throughout the study. Only male subjects were recruited because serum concentrations of total calcium and iPTH can be influenced by estrogens $[16,17]$.

The study was conducted in accord with the Helsinki Declaration of 1975 , as revised in 1983. The study protocol was approved by the Ethical committee of the Medical School Hannover, Germany. Informed consent was obtained from all subjects after they had received written information detailing the study and its purpose.

\subsubsection{Study Design and Methods}

In this randomized, single-blind, four-way crossover study, each subject served as his own control. Each subject ingested a single oral dose of one of the four different calcium preparations (CLC, CLM, CG, or CC) on four different days at two-week intervals. Each calcium salt contained $500 \mathrm{mg}$ calcium and was suspended in 250 $\mathrm{ml}$ of filtered apple juice (becker's bester, Germany). To minimize the differences in vitamin D status and to allow optimal $\mathrm{Ca}$ absorption, subjects were advised to consume $25 \mathrm{mg}$ of vitamin $\mathrm{D}_{3}$ (Hevert, Nussbaum, Germany) daily, two weeks prior to the study, and throughout the whole study period. Additionally, subjects were asked to minimize dietary calcium two days before each investigation day.

The subjects fasted from $8 \mathrm{pm}$ of the preceding day, except for drinking $500 \mathrm{ml} \mathrm{Ca-poor} \mathrm{water}(11.5 \mathrm{mg} \mathrm{Ca} / \mathrm{l})$ between 7.30 and $8 \mathrm{pm}$, and $300 \mathrm{ml}$ between 9.30 and 10 $\mathrm{pm}$. The subjects attended our laboratory at $7.30 \mathrm{am}$. Blood samples were drawn immediately before and 2, 4, $6,8,12$, and $24 \mathrm{~h}$ after ingestion of the calcium preparation. Urine was collected at the baseline and during the intervals 0-3, 3-6, 9-15, and 15-24 h. Energy expenditure-adjusted meals between $2100 \mathrm{kcal}$ and $3500 \mathrm{kcal}$ with low calcium and sodium content were given during the day. At $8.00 \mathrm{am}$, one of the calcium preparations was given with a standard breakfast (two slices of brown bread with spread, jam and honey, and one peach).

The primary outcome variables were serum concentrations of total $\mathrm{Ca}$ and intact parathyroid hormone (iPTH). Urine excretion of $\mathrm{Ca}$, sodium and creatinine was examined as a secondary outcome variable. Phosphate, albumin and the amount of 25 -hydroxyvitamin- $\mathrm{D}_{3}\left(25-\mathrm{OH}-\mathrm{D}_{3}\right)$ were determined only for control in the baseline blood sample.

Total serum $\mathrm{Ca}$ was quantified by flame/graphite furnace atomic absorption spectroscopy [14]; iPTH in the 
serum was measured by an electrochemilumines-cenceimmunoassay (Elecsys, Roche, Germany); concentration of vitamin D, by an antibody based chemilu-minescent system (DiaSorin, Saluggia, Italia); concentration of serum albumin, by an immunoturbidimetric test (Roche, Eppstein, Germany); and concentration of phosphate was analyzed by an ammoniumphosphomolybdate method (Roche Diagnostics, Mannheim, Germany). The concentration of calcium and sodium in urine was quantified by flame atomic emission spectroscopy, and the excretion of creatinine was analyzed by an enzyme test (CREA plusmethod; Roche Diagnostics, Mannheim, Germany).

\subsubsection{Pharmacokinetic Calculations and Statistics}

The maximum increase of total serum calcium concentration and the decreases of iPTH and serum phosphate for each subject and treatment group were calculated by subtracting the zero time (pre-dose) value from the maximum value observed post-dose. The increase in area under the curve (delta AUC) for serum calcium and the decrease of iPTH in area over the curve (delta AOC) were calculated using the trapezoidal rule approach.

The maximum urinary excretion of $\mathrm{Ca}$ was adjusted with the measured creatinine, and the ratio of calcium/ sodium was calculated. The increments in area under the curve for calcium/creatinine and calcium/sodium excretion in the urine were calculated using the trapezoidal rule approach.

Statistical analyses were performed using SPSS (statistical package for the social sciences) for Windows. The curves were plotted with Sigma-Plot for Windows. Normal distribution of the results was tested by using the Komolgorov-Smirnov-Test. All results are presented as mean \pm SD. Statistical differences within and between groups were determined by paired t-test, with the significance level set at $\mathrm{P}<0.05$ and $\mathrm{P}<0.07$ as a tendency to significance.

\section{Results}

\subsection{Ca-concentration and Solubility}

The Ca-content of the four salts differed by more than fourfold. CC contained $40.0 \% \mathrm{Ca}$, whereas CLM is composed of $18.1 \% \mathrm{Ca}, \mathrm{CLC}$ of $16.2 \%$ and CG only of $9.0 \% \mathrm{Ca}$ in one molecule. According to this, we calculated the recommended daily dose of every salt (Table 1).

The solubility of the four different calcium salts was tested in $21^{\circ} \mathrm{C}$ pure water and apple juice, respectively. Table 1 shows the notable differences in solubility between the salts. CLM and CLC are easily soluble in water and apple juice, significantly better than CG. CC is almost water-insoluble but in filtered apple juice with a $\mathrm{pH}$-value of $3.30,1.2 \mathrm{mg} / \mathrm{ml}$ pure $\mathrm{Ca}$ from $\mathrm{CC}$ could be dissolved.

\subsection{Bioavailibility}

\subsubsection{Absorption}

The bioavailability of the three different calcium salts CLC, CLM, and CC after a single dose of $500 \mathrm{mg}$ calcium was found to be almost identical (Table 2). Only CG seems to be slightly, but not significantly, inferior to the other three salts as measured by the total calcium serum content and the iPTH serum level 2, 4, 6, and $8 \mathrm{~h}$ after ingestion and calculated by the difference to the baseline.

The maximum total serum calcium increased by $7.6 \%$ $2 \mathrm{~h}$ after the ingestion of $500 \mathrm{mg}$ calcium as CLC $(+0.18$ $\pm 0.15 \mathrm{mmol} / \mathrm{l})$, by $7.4 \%$ after CLM $(+0.17 \pm 0.20$ $\mathrm{mmol} / \mathrm{l})$, by $5.5 \%$ after $\mathrm{CC}(+0.13 \pm 0.08 \mathrm{mmol} / \mathrm{l})$, and by $5.8 \%(+0.14 \pm 0.15 \mathrm{mmol} / \mathrm{l})$ after CG. Differences between the four salts were not significant (Table 2). changed to negative in the CG group after $8 \mathrm{~h}$, and negative amounts in the other three groups were detected after 24 h (see Figure 1).

Table 1. Concentration of $\mathrm{Ca}$ in the four different salts and solubility in water and apple juice.

\begin{tabular}{|c|c|c|c|c|c|c|}
\hline Ca-salt & $\begin{array}{l}\mathrm{Ca}- \\
\text { concentration }\end{array}$ & $\begin{array}{l}\text { Quantum of salt } \\
\text { needed for } 1 / 2 \text { RDA } \\
(500 \mathrm{mg} \mathrm{Ca})\end{array}$ & $\begin{array}{l}\text { Solubility in } \mathrm{H}_{2} \mathrm{O} \\
\left(21^{\circ} \mathrm{C}\right)\end{array}$ & $\begin{array}{l}\text { Solubility in apple } \\
\text { juice }\left(21^{\circ} \mathrm{C}\right)\end{array}$ & $\begin{array}{c}\text { max. soluble } \\
\mathrm{Ca} / 100 \mathrm{ml} \mathrm{H}_{2} \mathrm{O}\end{array}$ & $\begin{array}{c}\text { max. soluble } \mathrm{Ca} / 100 \mathrm{ml} \\
\text { apple juice }\end{array}$ \\
\hline$C L M$ & $18.1 \%$ & $2.75 \mathrm{~g}$ & $115 \mathrm{~g} / 1$ & $110 \mathrm{~g} / 1$ & $2082 \mathrm{mg}$ & $1991 \mathrm{mg}$ \\
\hline$C L C$ & $16.2 \%$ & $3.09 \mathrm{~g}$ & $98 \mathrm{~g} / 1$ & $80 \mathrm{~g} / 1$ & $1588 \mathrm{mg}$ & $1296 \mathrm{mg}$ \\
\hline$C C$ & $40.0 \%$ & $1.25 \mathrm{~g}$ & $\begin{array}{c}\text { almost insoluble } \\
0.014 \mathrm{~g} / 1\end{array}$ & $3.0 \mathrm{~g} / 1$ & $\begin{array}{l}\text { almost insoluble } \\
0.56 \mathrm{mg}\end{array}$ & $120 \mathrm{mg}$ \\
\hline$C G$ & $9.0 \%$ & $5.50 \mathrm{~g}$ & $30 \mathrm{~g} / 1$ & $50 \mathrm{~g} / 1$ & $270 \mathrm{mg}$ & $450 \mathrm{mg}$ \\
\hline
\end{tabular}


Table 2. Pharmacokinetic profile of total serum calcium after ingestion of CLC, CLM, CC, and CG.

\begin{tabular}{lcccc}
\hline & CC & CLM & CG & CLC \\
\hline AUC 0-2 $\mathrm{h}(\mathrm{mmol} / \mathrm{l} \times \mathrm{h})$ & $\mathrm{N}=20$ & $\mathrm{~N}=20$ & $\mathrm{~N}=20$ & $\mathrm{~N}=20$ \\
AUC 0-6 $(\mathrm{mmol} / \mathrm{l} \times \mathrm{h})$ & $0.13 \pm 0.08$ & $0.17 \pm 0.20$ & $0.14 \pm 0.15$ & $0.18 \pm 0.15$ \\
AUC 0-8 $(\mathrm{mmol} / \mathrm{l} \times \mathrm{h})$ & $0.17 \pm 0.74$ & $0.12 \pm 1.93$ & $0.21 \pm 2.20$ & $0.30 \pm 2.50$ \\
AUC 0-24 $(\mathrm{mmol} / \mathrm{l} \times \mathrm{h})$ & $0.07 \pm 1.28$ & $0.24 \pm 0.95$ & $-0.36 \pm 1.87$ & $0.21 \pm 0.79$ \\
\hline
\end{tabular}

$42.5 \%$ after CLM $(-1.61 \pm 0.78 \mathrm{pmol} / \mathrm{l})$, by $42.5 \%$ after CC $(-1.61 \pm 0.85 \mathrm{pmol} / \mathrm{l})$, and by $33.3 \%$ after CG $(-1.28$ $\pm 0.81 \mathrm{pmol} / \mathrm{l})$. The differences between the four salts were not significant. However, a tendency to significance could be shown in the AOC $(0-6 \mathrm{~h})(\mathrm{p}=0.058)$. The AUCs were calculated for the periods $0-6 \mathrm{~h}, 0-8 \mathrm{~h}$ and 0-24 h after ingestion (see Table 3 and Figure 2).

\subsubsection{Urinary Excretion}

Secondary outcome variables were measured in the urine. The maximum total calcium excretion amounted to 4.80 $\pm 2.88 \mathrm{mmol} / \mathrm{l}$ after ingestion of $\mathrm{CC}, 4.63 \pm 3.25 \mathrm{mmol} / \mathrm{l}$ after $\mathrm{CG}, 4.32 \pm 2.18 \mathrm{mmol} / 1$ after CLC, and $3.88 \pm 1.64$ $\mathrm{mmol} / \mathrm{l}$ after consumption of CLM. We adjusted the total calcium levels with excreted creatinine and sodium in the urine relative to the intra-individual variability between the subjects.

The maximum creatinine-adjusted calcium excretion was found after ingestion of CLC $(0.60 \pm 0.23 \mathrm{mmol} / \mathrm{l})$, followed by CLM $(0.57 \pm 0.25 \mathrm{mmol} / \mathrm{l}), \mathrm{CC}(0.53 \pm 0.16$ $\mathrm{mmol} / \mathrm{l})$, and $\mathrm{CG}(0.47 \pm 0.23 \mathrm{mmol} / \mathrm{l})$ (not significant). Furthermore, $\mathrm{T}_{\max } \mathrm{Ca}$ (creatinine-adjusted) excretion was reached significantly faster after ingestion of $\mathrm{CG}(\mathrm{p}=<$ 0.001), and AUC 0-6 h Ca-excretion was significantly higher after ingestion of CG $(p=0.042)$ compared to the other salts.

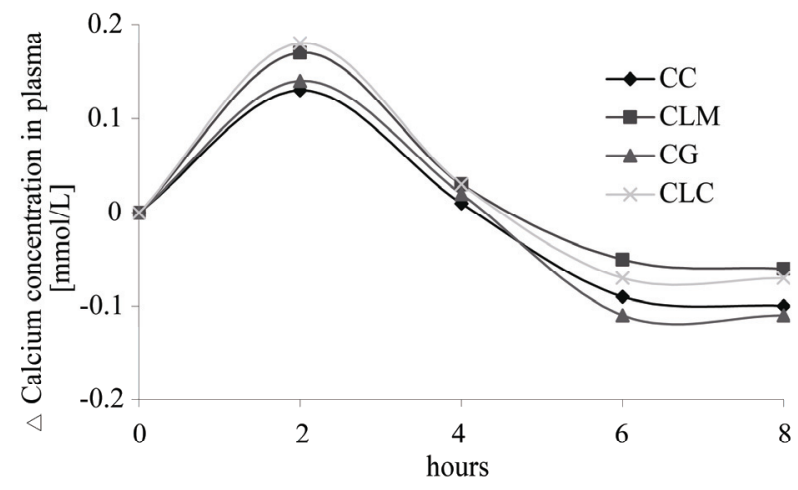

Figure 1. Time-course of the $\Delta$ serum calcium for the four calcium sources over 8 h.

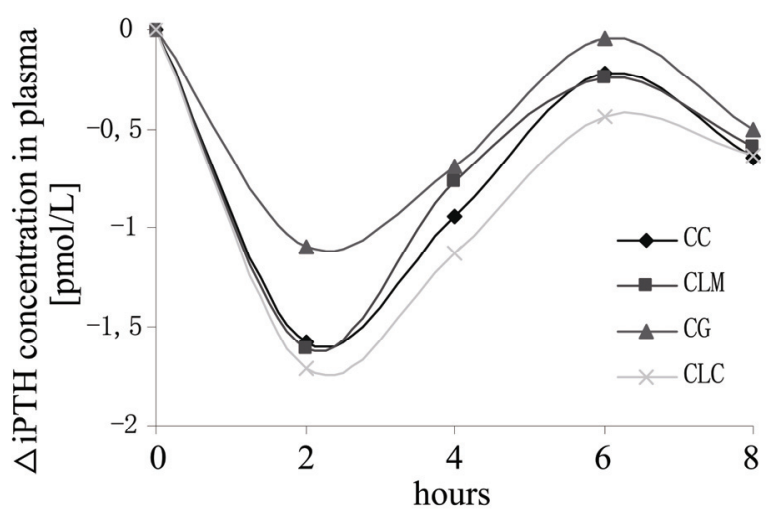

Figure 2. Time-course of $\Delta$ serum iPTH concentration for the four calcium sources over $8 \mathbf{h}$.

Urinary sodium/calcium excretion (0-24 h) was comparable to creatinine-adjusted $\mathrm{Ca}$ excretion; the highest amount was detected after ingestion of CLC $(83.8 \pm 28.7$ $\mathrm{mmol} / \mathrm{l})$, followed by CLM $(71.6 \pm 23.8 \mathrm{mmol} / \mathrm{l}), \mathrm{CG}$ $(71.4 \pm 25.8 \mathrm{mmol} / \mathrm{l})$, and $\mathrm{CC}(70.9 \pm 18.0 \mathrm{mmol} / \mathrm{l})$. The AUC 0-12 h and the AUC 0-24 h for the sodium/calcium excretion were marginally but significantly lower after the ingestion of CG compared to the other compounds ( $p$ $=0.001$ and $\mathrm{p}=<0.001$, respectively).

\section{Discussion}

The four Ca-preparations tested induced a significant increase in serum $\mathrm{Ca}$ and a significant fall in serum iPTH levels, also indicating a $\mathrm{Ca}$ increase in young male volunteers after a single dose of $500 \mathrm{mg} \mathrm{Ca}$. These findings are in agreement with previous papers showing significant increases in serum $\mathrm{Ca}$ or suppressing iPTH secretion after a single dose of $\mathrm{Ca}[11,15,18]$. The current study showed a slightly superior, but not significant, increase of total serum $\mathrm{Ca}$ after ingestion of the two new calcium salts CLC and CLM. The suppression of iPTH was less effective after $\mathrm{CG}$ compared to the other three salts, and the urinary excretion maximum of calcium was lower after ingestion of CG. Therefore, we postulate a slightly better absorption of the three salts CLC, CLM and CC compared to $\mathrm{CG}$. 
Table 3. Pharmacokinetic profile of total serum iPTH after administration of CLC, CLM, CC, and CG.

\begin{tabular}{|c|c|c|c|c|}
\hline & $\mathrm{CC}$ & CLM & CG & CLC \\
\hline & $\mathrm{N}=20$ & $\mathrm{~N}=20$ & $\mathrm{~N}=20$ & $\mathrm{~N}=20$ \\
\hline AOC 0-2 h $(\mathrm{pmol} / 1 \times \mathrm{h})$ & $-1.61 \pm 0.85$ & $-1.61 \pm 0.78$ & $-1.28 \pm 0.81$ & $-1.72 \pm 0.80$ \\
\hline AOC $0-6$ h $(\mathrm{pmol} / 1 \times \mathrm{h})$ & $-5.27 \pm 3.80$ & $-4.99 \pm 4.03$ & $-3.75 \pm 3.96$ & $-6.11 \pm 3.51$ \\
\hline AOC $0-8$ h $(\mathrm{pmol} / 1 \times \mathrm{h})$ & $-6.15 \pm 5.18$ & $-5.82 \pm 5.44$ & $-4.29 \pm 5.54$ & $-7.18 \pm 4.59$ \\
\hline AOC $0-24 \mathrm{~h}(\mathrm{pmol} / 1 \times \mathrm{h})$ & $-6.46 \pm 19.95$ & $-8.20 \pm 18.41$ & $-8.92 \pm 14.03$ & $-7.57 \pm 12.08$ \\
\hline
\end{tabular}

However, $\mathrm{Ca}$ intake prior to the ingestion of the $\mathrm{Ca}-$ preparations could affect intestinal fractional Ca absorption [19]. While a high calcium intake suppresses the fractional calcium absorption, a low calcium intake stimulates the fraction that is absorbed. Dawson-Hughes et al. found that most of this intestinal adaptation occurs within one week [20]. Sodium intake also has important effects on the calcium metabolism [21]. To overcome the varying effects of prevailing dietary calcium and sodium intake during the four study phases, we restricted $\mathrm{Ca}$ and sodium intake during the whole study period and standardized the $\mathrm{Ca}$ and sodium intake on the four study days.

In this study we tested two new salts, CLM and CLC, which were developed as easily water-soluble salts with a rather substantial content of $\mathrm{Ca}$. They were compared with two popular calcium salts, $\mathrm{CC}$ and $\mathrm{CG}$, in water and apple juice solubility and bioavailability. $\mathrm{CC}$ is the most consumed calcium supplement in the US and Europe [11], but it is almost insoluble in water. We found a significantly lower solubility of CC than the other three salts even in acidic apple juice. CG is water-soluble in moderate quantities, but the content of calcium is low. It is used for people with $\mathrm{CC}$ intolerance and to fortify beverages. Nevertheless, aqueous solubility is only a technological advantage but not absolutely necessary for the bioavailability $[15,22]$ because Ca needs only to be soluble in the acid medium of the stomach in order to be absorbed. However, people with achlorhydria or elderly people with reduced or absent gastric acid production have a very impaired absorption of $\mathrm{CC}$ when it is ingested alone $[23,24]$. In this case, $\mathrm{CC}$ can not be recommended; $\mathrm{pH}-$ adjusted citrate forms of $\mathrm{Ca}$ and water-soluble forms are a good alternative for these people. Ingesting $\mathrm{CC}$ together with a meal leads to an almost normal absorption in achlorhydric subjects [25].

CLM and CLC are therefore suitable for the fortification of beverages, like the established salt calcium citrate malate. Soft drinks, especially apple or orange juice which are widely consumed in the US and Europe, represent a good basis for $\mathrm{Ca}$ enrichment and therefore for improving the $\mathrm{Ca}$ intake of the population. Calcium fortification of apple and orange juices may be a potentially important vehicle for increasing the dietary intake of calcium, especially for those who do not or cannot consume dairy products. Furthermore, tests with rats revealed an almost better bioavailability of $\mathrm{Ca}$ from fortified juices than from milk [26]. The tolerable upper limit - the amount of calcium that can be taken during the whole lifespan without adverse effects - for calcium is $2500 \mathrm{mg} / \mathrm{d}[11,14]$. So a fortification of $250 \mathrm{mg} \mathrm{Ca}$ per $100 \mathrm{ml}$ juice would be safe and effective, assuming a consumption of one glass of fruit juice daily.

There are several limitations to this preliminary study. We carried out the study with young male subjects. Consequently, it must be shown whether the bioavailability is comparable in women and especially in elderly people. There may have been insufficient measuring points to identify the exact serum Ca-maximum and iPTH-minimum. We therefore recommend measuring points after $1-8$, and $12 \mathrm{~h}$ for future Ca-bioavailability studies.

In summary, CLM und CLC might be seen as good water-soluble salts with a satisfactory $\mathrm{Ca}$ content and $\mathrm{Ca}$ availability comparable to the popular salts, CC and CG. We conclude that CLC and CLM appear to be a very good choice for the fortification of beverages to increase the daily $\mathrm{Ca}$ intake.

Acknowledgement: The study supplements used in this study were a gift from Dr. Paul Lohmann GmbH KG, Emmerthal, Germany.

\section{REFERENCES}

[1] R. L. Bailey, K. W. Dodd, J. A. Goldman, J. J. Gahche, J. T. Dwyer, A. J. Moshfegh, C. T. Sempos and M. F. Picciano, "Estimation of Total Usual Calcium and Vitamin D Intakes in the United States," Journal of Nutrition, Vol. 140, No. 4, 2010, pp. 817-822.

[2] FaNBIoM, Standing Committee on the Scientific Evaluation of Dietary Reference Intakes, "Dietary Reference Intakes for Calcium, Phosphorus, Magnesium, Vitamin D and Fluoride," 1997.

[3] J. Y. Reginster, D. Denis, V. Bartsch, R. Deroisy, B. Zegels and P. Franchimont, "Acute Biochemical Variations Induced by Four Different Calcium Salts in Healthy Male Volunteers," Osteoporosis International, Vol. 3, No. 5, 1993, pp. 271-275.

[4] National Academy of Science, http://www.iom.edu/ 
Object.File/Master/54/391/Summary Listing.pdf, 2009.

[5] S. Meacham, D. Grayscott, J. J. Chen and C. Bergman, "Review of the Dietary Reference Intake for Calcium: Where do we Go from Here?" Critical Reviews in Food Science and Nutrition, Vol. 48, No. 5, 2008, pp. 378384.

[6] Max Rubner-Institut, http://www.bmelv.de/cln_045/ nn_1196770/SharedDocs/downloads/03-Ernaehrung/ NV̄S2/NVS_ErgebnisberichtTeil2,templateId=raw, property $=$ publicationFile.pdf/NVS Ergebnisbericht Teil2.pdf, 2008.

[7] J. Ma, R. A. Johns and R. S. Stafford, "Americans are not Meeting Current Calcium Recommendations," American Journal of Clinical Nutrition, Vol. 85, No. 5, 2007, pp. 1361-1366.

[8] K. Rafferty, G. Walters, and R. P. Heaney, "Calcium Fortificants: Overview and Strategies for Improving Calcium Nutriture of the U.S. Population," Journal of Food Science, Vol. 72, No. 9, 2007, pp. R152-R158.

[9] B. R. Martin, C. M. Weaver, R. P. Heaney, P. T. Packard and D. L. Smith, "Calcium Absorption from Three Salts and $\mathrm{CaSO}(4)$-Fortified Bread in Premenopausal Women," Journal of Agricultural and Food Chemistry, Vol. 50, No. 13, 2002, pp. 3874-3876.

[10] H. J. Heller, A. Stewart, S. Haynes and C. Y. Pak, "Pharmacokinetics of Calcium Absorption from Two Commercial Calcium Supplements," Journal of Clinical Pharmacology, Vol. 39, No. 11, 1999, pp. 11511154.

[11] D. A. Straub, "Calcium Supplementation in Clinical Practice: A Review of Forms, Doses, and Indications," Nutrition in Clinical Practice, Vol. 22, No. 3, 2007, pp. 286-296.

[12] M. S. Sheikh, C. A. Santa Ana, M. J. Nicar, L. R. Schiller, and J. S. Fordtran, "Gastrointestinal Absorption of Calcium from Milk and Calcium Salts," The New England Journal of Medicine, Vol. 317, No. 9, 1987, pp. 532-536.

[13] M. G. Nowak, B. Szulc-Musiol and F. Ryszka, "Pharmacokinetics of Calcium from Calcium Supplements in Healthy Volunteers," Pakistan Journal of Pharmaceutical Science, Vol. 21, No. 4, 2008, pp. 109-112.

[14] R. P. Heaney, "Calcium Supplements: Practical Considerations," Osteoporosis International, Vol. 1, No. 2, 1991, pp. 65-71.

[15] L. Gueguen and A. Pointillart, "The Bioavailability of
Dietary Calcium," Journal of the American College of Nutrition, Vol. 19, No. (Suppl. 2), 2000, pp. S119S136.

[16] J. J. Jacono and J. M. Robertson, "The Effects of Estrogen, Progesterone, and Ionized Calcium on Seizures during the Menstrual Cycle of Epileptic Women," Epilepsia, Vol. 28, No. 5, 1987, pp. 571-577.

[17] R. M. Pitkin, W. A. Reynolds, G. A. Williams, and G. K. Hargis, "Calcium-Regulating Hormones during the Menstrual Cycle," Journal of Clinical .Endocrinology and Metabolism, Vol. 47, No. 3, 1978, pp. 626-632.

[18] R. P. Heaney, "Bone Health," American .Journal of Clinical Nutrition, Vol. 85, No. 1, 2007, pp. S300$\mathrm{S} 303$.

[19] R. P. Heaney, C. M. Weaver and M. L. Fitzsimmons, "Influence of Calcium Load on Absorption Fraction," Journal of Bone and Mineral Research, Vol. 5, No. 11, 1990, pp. 1135-1138.

[20] B. Dawson-Hughes, D. T. Stern, C. C. Shipp and H. M. Rasmussen, "Effect of Lowering Dietary Calcium Intake on Fractional Whole Body Calcium Retention," Journal of Clinical .Endocrinology and Metabolism, Vol. 67, No. 1, 1988, pp. 62-68.

[21] L. K. Massey and S. J. Whiting, "Dietary Salt, Urinary Calcium, and Kidney Stone Risk," Nutrition Reviews, Vol. 53, No. 5, 1995, pp. 131-139.

[22] R. P. Heaney, R. R. Recker and C. M. Weaver, "Absorbability of Calcium Sources: The Limited Role of Solubility," Calcified Tissue International, Vol. 46, No. 5, 1990, pp. 300-304.

[23] P. Sipponen and M. Harkonen, "Hypochlorhydric Stomach: A Risk Condition for Calcium Malabsorption and Osteoporosis?" Scandinavian .Journal of Gastroenterology, Vol. 45, No. 2, 2010, pp. 133-138.

[24] R. F. Shangraw, "Factors to Consider in the Selection of a Calcium Supplement," Public Health Reports, Vol. Vol. 104, No. Suppl., 1989, pp. 46-50.

[25] R. R. Recker, "Calcium Absorption and Achlorhydria," The New England Journal of .Medicine, Vol. 313, No. 2, 1985, pp. 70-73.

[26] M. B. Andon, M. Peacock, R. L. Kanerva and J. A. de Castro, "Calcium Absorption from Apple and Orange Juice Fortified with Calcium Citrate Malate (CCM)," Journal of the American College of Nutrition, Vol. 15, No. 3, 1996, pp. 313-316.

\section{Abbreviations}

AUC: area under the curve, Ca: calcium, CC: calcium carbonate, CG: calcium gluconate, CLC:calcium lactate citrate, CLM: calcium lactate malate, iPTH: intact parathyroid hormone, RDA:recommended daily allowance 